\title{
Racismo y discriminación en programas de televisión colombianos. El caso del "soldado Micolta" del programa humorístico Sábados Felices
}

\author{
Juan Pablo Gómez Moreno \\ Johan Sebastián Castañeda Pisco ${ }^{\mathrm{I}}$
}

\section{Introducción}

La Real Academia de la Lengua Española (2014) nos indica que racismo es "una exacerbación del sentido racial de un grupo étnico que suele motivar la discriminación o persecución de (...) otros con los que convive". Por consiguiente, el racismo y la segregación socio-racial que involucra a la población devienen de problemáticas o practicas racistas que han ocurrido históricamente.

Así mismo, el contexto socio-racial que vive la población afro en Colombia genera exclusión, invisibilidad, intolerancia y hasta burla por parte de los medios de comunicación. En la misma línea, el poder que ejerce un medio de comunicación sobre su audiencia es persuasivo y simbólico, en la medida que tiene de la disponibilidad de un mayor o menor control en los receptores e indica cómo realizar algunas de sus acciones cotidianas.

1 Estudiantes de la Facultad de Comunicación Social de la Universidad Santo Tomás. 
Por consiguiente, un medio de comunicación según Guillermo Orozco (2001) ejerce un efecto indirecto en el receptor, debido a que controlan sus intenciones, creencias, pensamientos, conocimientos, entre otras cosas, de los sujetos al intentar construir una "realidad". A raíz de esto, los medios de comunicación de a poco van configurando la mente del individuo y estos se desenvolverán según el conocimiento que tengan del medio.

De igual manera "los medios informativos no son las únicas instituciones de élite que están implicadas en la reproducción del racismo. Sin embargo, ellos son los actores más eficaces y exitosos en el manejo del consenso étnico y en la fabricación del consentimiento público" (Van Dijk, 1997, p. 15), es decir, los temas referentes de cobertura que hacen los medios de comunicación van enfocados a un “esquema práctico para definir e interpretar los acontecimientos étnicos y una estrategia de dominación para definir a los otros" (Duplatt, 2009 , p. 6), en donde se genera una dicotomía entre blancos y negros, en donde la población blanca es comprensiva, tolerante y amistosa y los otros son revolucionarios, amenazantes y demás.

Para seguir en la línea de Van Dijk, “(...) el racismo ofrece un marco estructural que facilita y reproduce las conveniencias de los grupos de poder dominantes" (1997, p. 15). En donde lo blancos se benefician de este tipo de estructuras para legitimar y generar algún tipo de poder. Además son esas elites de poder (medios de comunicación) las cuales aportaran unos estigmas, prototipos, prejuiciosos en la sociedad, debido que el discurso empleado por estas industrias, acompañado de una caracterización generan un prototipo del individuo afroamericano en Colombia.

A raíz de lo anterior, el presente artículo académico pretender responder al interrogante: ¿Cómo a través del discurso, la corporalidad, caracterización, kinésica y demás elementos del personaje humorístico colombiano "Micolta" del programa Sábados Felices se logra estructurar y configurar un estereotipo de la población afrocolombiana? Y además de analizar cómo un personaje humorístico de Sábados Felices "soldado Micolta" representa el racismo frontal, homogeniza y estereotipa a la población afrocolombiana, el cual responde a nuestro objetivo general. 
Ahora bien, el personaje de humor "Micolta", interpretado por Roberto Lozano en el programa humorístico de Sábados Felices del Canal Caracol, es un personaje que ha causado indignación e inconformismo en la población afroamericana por la manera en que "Micolta" es caracterizado.

El caso fue denunciado por parte del colectivo Chao Racismo, en cabeza de su presidente Ray Charrupi, quien el pasado mes de octubre del 2015 presentó acciones legales contra Roberto Lozano por la caracterización indebida y burlesca de una persona afro agrediendo así la dignidad de los afrocolombianos, Ray Charrupi, presidente de Chao Racismo expresó:

(...) Estamos seguros que habrán opiniones necias que considerarán improcedente este reclamo; de la misma forma que hubo opositores a que los negros fueran liberados, las mujeres votaran y que Colombia logrará su independencia; lucharemos contra las narconovelas y para que las personas del mismo sexo se casen. No nos sorprende la irracionalidad, sin embargo la combatimos hasta forzar la lógica, desde el corazón o la mente; pero no podemos seguir comportándonos como una sociedad vergonzosamente subdesarrollada que hace humor, vende productos o servicios ridiculizando y denigrando la dignidad de personas, diversidades, poblaciones y territorios. (El pais.com, 2015)

Argumentos que de alguna manera son válidos, determinando que existe en los medios masivos y en sus discursos formas de racismo y burla de las interpretaciones estereotipadas de la cultura afrocolombiana, encasillándolas muchas veces de personas poco capaces y muchas interpretaciones negativas. A raíz de lo anterior, se empleó como metodología el análisis de contenidos y audiencias, este tipo de herramienta efectúa simultáneamente dos elementos. Por una parte el discurso empleado por el "soldado Micolta" y por otro lado la recepción que genera en los segmentos específicos o grupos focales a los que va dirigido este mensaje. Cuenta con la característica que dentro de su metodología ofrece aspectos de los estudios culturales en la medida que los mensajes mediáticos son discursos codificados. De esta manera, 
la audiencia o grupo focal crea criterios de razonamiento frente a lo que se está viendo.

En la misma línea, Guillermo Orozco (2001) refiere a la audiencia como un elemento de análisis, debido a que el receptor capta el mensaje, lo interpreta y re-transmite en su cotidianidad. De esta manera, es propicio aclarar la categoría de estereotipo desde Homi K. Bhabha, teórico del poscolonialismo de origen indio, como "una forma de conocimiento e identificación que vacila entre lo que siempre está "en su lugar" ya conocido, y algo que debe ser repetido ansiosamente" (Bhabha, 2007 , p. 12), en relación con una identidad racial afro, que encontramos al día dentro de la industria cultural y específicamente de este tipo de programas de entretenimiento, lleva a la audiencia a múltiples interacciones con la televisión y a la larga propicia diferentes participaciones generando una serie de imaginarios sociales (Jaramillo, 2014).

\section{Análisis de caso}

Desde el manejo del prejuicio que se tiene de la comunidad afro se instaura un tipo de racismo simbólico que excluye y que agrede de una forma que se establece en el imaginario colectivo estereotipos negativos sobre la población afro.

El prejuicio sutil aparecerá sobre todo cuando las capacidades de las personas que sufren el prejuicio sean ambiguas pero no cuando se observe con claridad sus habilidades. Son formas de racismo sutil a) el racismo simbólico rechazan el racismo tradicional pero aún expresan prejuicio indirectamente, b) el racismo ambivalente en el que se experimentan un conflicto emocional entre sentimientos positivos y negativos hacia grupos raciales estigmatizados, c) el racismo moderno, en el que se ve al racismo como incorrecto, pero se visualiza a las minorías raciales haciendo peticiones y d) racismo aversivo en el que se cree en los principios igualitarios tales como igualdad racial pero se tiene una aversión personal hacia las minorías raciales. (Aguilar, 2011, p. 7) 
Así se presenta en las intervenciones del "soldado Micolta” en el programa de televisión de Sábados Felices, el cual se emite en la franja prime time de los días sábado, en donde el soldado homogeniza a los hombres afrocolombianos desde diferentes aspectos y se ve un tipo de racismo y prejuicio sutil.

Entrando en materia del cuerpo del análisis, en donde principalmente tomaremos una pieza audiovisual de una presentación del 15 de abril de 2012, interpretación del "soldado Micolta” y Colombia en el elenco de Sábados Felices. Donde se tomará textualmente el discurso humorístico y se analizará a la luz de autores que aportan a la comprensión de cómo se refuerzan los estereotipos negativos en este caso; que son ordinarios o toscos, sexualmente las mujeres afro y los hombres afro tienen apetitos sexuales desenfrenados, irracionales, bárbaros y salvajes, lo que lleva a observar en este la afirmación generalizada y homogeneizadora de los estereotipos:

- En primera instancia considera dentro de su dialéctica y matiz de voz que todos tienen el mismo acento y pronuncian mal el idioma español.

- Segundo, “Micolta” representa un eufemismo, fanfarronería, infantilismo, como lo quiera denominar, en la medida que los hombres afrocolombianos no han tenido la capacidad de madurar, de usar su intelecto. Por otra parte, durante sus intervenciones "Micolta" caracterizaba un negro: torpe, perezoso y burlesco. Por consiguiente, se parte de una serie de prejuicios racistas que han construido contra la población afro desde hace varios siglos en diversos continentes.

Siendo consecuentes con nuestra investigación implementamos una matriz de análisis de caso $^{2}$ que nos permite organizar los contenidos (presentaciones del "soldado Micolta", y sus diferentes interpretaciones) haciendo un análisis de los diferentes componentes lingüísticos característicos de la población afrocolombiana.

2 Matriz de análisis de caso, tabla número 1, véase en anexo. 
Ejemplo del primer caso:

Colombia: - "pero entonces porque no me dices algo bonito pero decímelo a mí”

Micolta: "bueno te voy a decir algo bonito, hoy por la noche te voy a chupar trompa"

Colombia: - "vo [...] si sos [...] ordinario, vos meterle romanticismo, metele $[\ldots]$ emoción, decime algo ma [...] bonito.

Micolta: "entonces voy a meterle romanticismo, hoy por la noche te voy a chupar trompa bajo la luz de la luna".

Colombia: - "vo [...] si sos [...] ordinario. (Presentación "Micolta y Colombia”, 2012)

Es explícitamente en el caso "Micolta" donde se vuelve a caer en esa afirmación en un medio masivo de comunicación de estereotipos negativos y que de alguna manera excluyen y generan imaginarios errados en la gran mayoría de casos. En este ejemplo vemos cómo se le atribuye de ordinario y poco educado al hombre afro al expresar sus sentimientos y emociones a la mujer. Manejando el concepto de estereotipos desde Homi Bhabha (2007) quien lo determina como "una forma de conocimiento e identificación que vacila entre lo que siempre está "en su lugar", ya conocido, y algo que debe ser repetido ansiosamente...como si la esencial duplicidad del asiático y la bestial licencia sexual del africano que no necesitan pruebas, nunca pudieran ser probadas en el discurso (...)” (Jaramillo, 2014, p. 91).

Ejemplo del segundo caso:

Micolta: -"vo [...] decime negra ¿Con cuántos hombres haz dormido?

Colombia: - “¿querés que te diga la verdad?” Micolta: - "sí"

Colombia: -"pues la verdad el único hombre que he dormido es contigo"

Micolta: - ¿Verdad negra”?

Colombia: - "si porque los demás no me han dejado dormir” 
Micolta: - “jesta si es mucha fundurundundinga ala! (Presentación “Micolta y Colombia”, 2012)

Es en este apartado donde se es explicito la exacerbación de los estereotipos negativos en este caso que las mujeres afro y hombres afro tienen apetitos sexuales desenfrenados.

Ejemplo del tercer caso:

Colombia:-“mira que tengo un problema”

Micolta:-“¿Qué tenés?

Colombia:-“con mi sobrino"

Micolta:-“¿Qué le paso a tu sobrino?”

Colombia:-“nada, mira que el vendió el blasberry [...] ese teléfono blasberry $[\ldots .$.$] que disque para comprar marihuana".$

Micolta:-“ay pero gracias a dios dejo ese vicio del blasberry [...]” Colombia:-“usted si nunca le pone seriedad a la vaina”. (Presentación “Micolta y Colombia”, 2012)

"Es necesario precisar que esta reflexión hace referencia a un contexto muy concreto: una región aislada de ciertos modelos de desarrollo, en donde la pobreza limita buena parte de los anhelos y restringe críticamente las posibilidades de las personas y donde la opción de un trabajo para los negros como profesionales es una oportunidad relativamente reciente. Por eso muchos de ellos buscan capacitarse con la esperanza de romper el aislamiento, vencer la pobreza y obtener el reconocimiento social" (Vigoya, s.f., p. 8).

Aunque si bien es cierto que la población afrocolombiana es una de las comunidades más pobres del país, hacer mofa sobre esto mediáticamente no contribuye en lo más mínimo para contrarrestar esta delicada realidad que solventa un problema estructural en la cultura, ya que es dónde podemos ver las consecuencias sociales debido a estas afirmaciones estereotipadas, siempre presentando una gran desventaja en cuanto al reconocimiento e imaginario instaurado en los ciudadanos, reproduciendo negativamente la idea que la población afro presenta una precaria formación académica 
y capacidad intelectual; es en este apartado donde se reafirman mediante la burla e interpretación indebida, una discriminación muy fuerte al reconocimiento de las capacidades de la población afro generalmente.

Esta discriminación consecuencia de los imaginarios y estereotipos conlleva a unas implicaciones sociales, económicas, laborales y culturales ya que se puede ver en diferentes niveles como lo afirma Jorge Aguilar:

La discriminación implica poner a miembros de un grupo en desventaja o tratarlos injustamente por pertenecer a un grupo. La “discriminación personal” se refiere al acto de discriminación llevado a cabo por individuos (Una persona que se niega a contratar a otra por su raza), mientras que la "discriminación institucional" se refiere a políticas o prácticas discriminatorias llevadas a cabo por organizaciones y otras instituciones (Las políticas de migración de un país). (Aguilar, 2011, p. 3)

De esta manera podemos hacer aseveraciones en cuanto las implicaciones de la reproducción de los estereotipos negativos mediante la mofa a través de un programa de televisión, ya que muchas veces no nos damos cuenta y pareciera realmente invisible sus consecuencias para la población afro.

\section{Conclusión}

Pudimos observar en la matriz anterior el desglose de elementos que ayudan a esclarecer los múltiples componentes que podemos encontrar en el caso del "soldado Micolta" del programa humorístico Sábados Felices como el manejo reiterativo de estereotipos negativos que refuerzan imaginarios de racismo y discriminación en programas de televisión colombianos.

Si de alguna manera intentamos justificar este tipo de espectacularidad es que se hace con el fin del humor y no se encuentra ningún sentido ofensivo, Ray Charrupi, presidente de Chao Racismo explica que Roberto Lozano, quien interpretaba al "soldado Micolta" "decidió no interpretar más este personaje, por cuanto si bien no se genera 
ningún tipo de agresión a ninguna población o comunidad ha entendido que el grueso de la población que se auto-reconoce afro, encuentra en el personaje del 'soldado Micolta' una ridiculización y por ende vulneración a la dignidad de los afrocolombianos y los ciudadanos en general que advierten contenido discriminatorio en este personaje” (semana.com, octubre de 2015).

Y como es usual en este contexto se está ignorando que existe manera muy subjetiva e indirecta de ejercer o propiciar violencia simbólica contra otros. El teórico neerlandés Teun van Dijk dice al respecto:

Precisamente por su naturaleza sutil y simbólica, muchas formas del «nuevo» racismo son discursivas. Se expresan, se promulgan y se confirman con texto y habla: conversaciones cotidianas, reuniones de consejos de administración, entrevistas de trabajo, políticas, leyes, debates parlamentarios, propaganda política, libros de texto, artículos académicos, películas, programas de televisión y noticias en la prensa, entre cientos de otros géneros. (Van Dijk, 2005, p. 37)

Desde el nuevo racismo, nuestro punto de enunciación es desde el lenguaje corporal o hablado desde los medios de comunicación el cual en el análisis se puede observar en este caso los prejuicios que pueden representarse y legitimarse a diario por este tipo de caracterizaciones. Debido a que no solamente el discurso trae consigo consecuencias y condiciones en los contextos comunicativos e interactivos en la sociedad, sino que también afecta el discurso cotidiano, además de entes impartidores de conocimiento como la escuela, además de otros organismos de la sociedad, en donde para la época "los emisores institucionales son el sistema educativo en general y los medios” (Raiter, 2002, p. 2).

\section{Referencias}

Aguilar, J. (2011). Prejuicios, Estereotipos y Discriminación. Recuperado de: http://www.conductitlan.net/psicologia_organizacional/prejuicio_estereotipo_discriminacion.pdf

Duplatt, A. (2009). “Los periodistas y el orden social”, en Narrativas, nro. 18, abril-junio de 2009. Recuperado de: www.narrativas.com.ar 
García, M. Navas, M. Cuadrado, I. \& Molero, F. (2003). Inmigración y prejuicios: actitudes de una muestra de adolescentes almerienses. España. Acción psicológica, Pp: 2, 137-147. Pp. 155-175. Recuperado de: file://C:/ Users/D!EGOM3Z\%20!!/Downloads/rie27a07.PDF

Jaramillo, J.I (2014). Una cátedra electiva de estudios afrocolombianos y afrolatinoamericanos desde una facultad de comunicación social para la paz. GT1: Comunicación Intercultural y Folkcomunicación. Recuperado de: http://congreso.pucp.edu.pe/alaic2014/wpcontent/uploads/2013/09/Ponencia-Jorge-Iv\%C3\%A1n-Jaramillo-Colombia-GT1-_2_.pdf

Los siameses show. (2012, abril, 16). Micolta y Colombia [Archivo de video]. Recuperado de https://www.youtube.com/watch?v=f09m4Pp5jqw

Orozco, G. (2001). Audiencias, televisión y educación: una deconstrucción pedagógica de la 'televidencia' y sus mediaciones. Revista Iberoamericana.

Raiter, A. (2002). "Representaciones sociales” Buenos Aires, Editorial UBA. Recuperado de: http://www.filo.uba.ar/contenidos/carreras/letras/catedras/sociolinguistica/sitio/docs/sitio/represen.pdf

Real Academia Española[RAE].(2014). Definición racismo. Edición Tricentenario. Rae.es. Recuperado de http://dle.rae.es/?id=V0WHEQ2

Van Dijk, T. (1997). Racismo y análisis crítico de los medios. Barcelona. Paidós. Recuperado de: http://www.discursos.org/oldarticles/Discurso \%20 racista.pdf

Van Dijk, T. (2005). Nuevo racismo y noticias. Inmigración, género y espacios urbanos. Los retos de la diversidad. Pp: 33-56. Recuperado de: http:// www.discursos.org/oldarticles/Nuevo $\% 20$ racismo $\% 20 \mathrm{y} \% 20$ noticias.pdf

Vigoya, V. (s.f.). Dionisios negros. Estereotipos sexuales y orden racial en Colombia. Recuperado de: http://lasa.international.pitt.edu/LASA98/ ViverosVigola.pdf 
RACISMO Y DISCRIMINACIÓN EN PROGRAMAS DE TELEVISIÓN COLOMBIANOS. EL CASO DEL “soldado Micolta” Del programa humorístico Sábados Felices

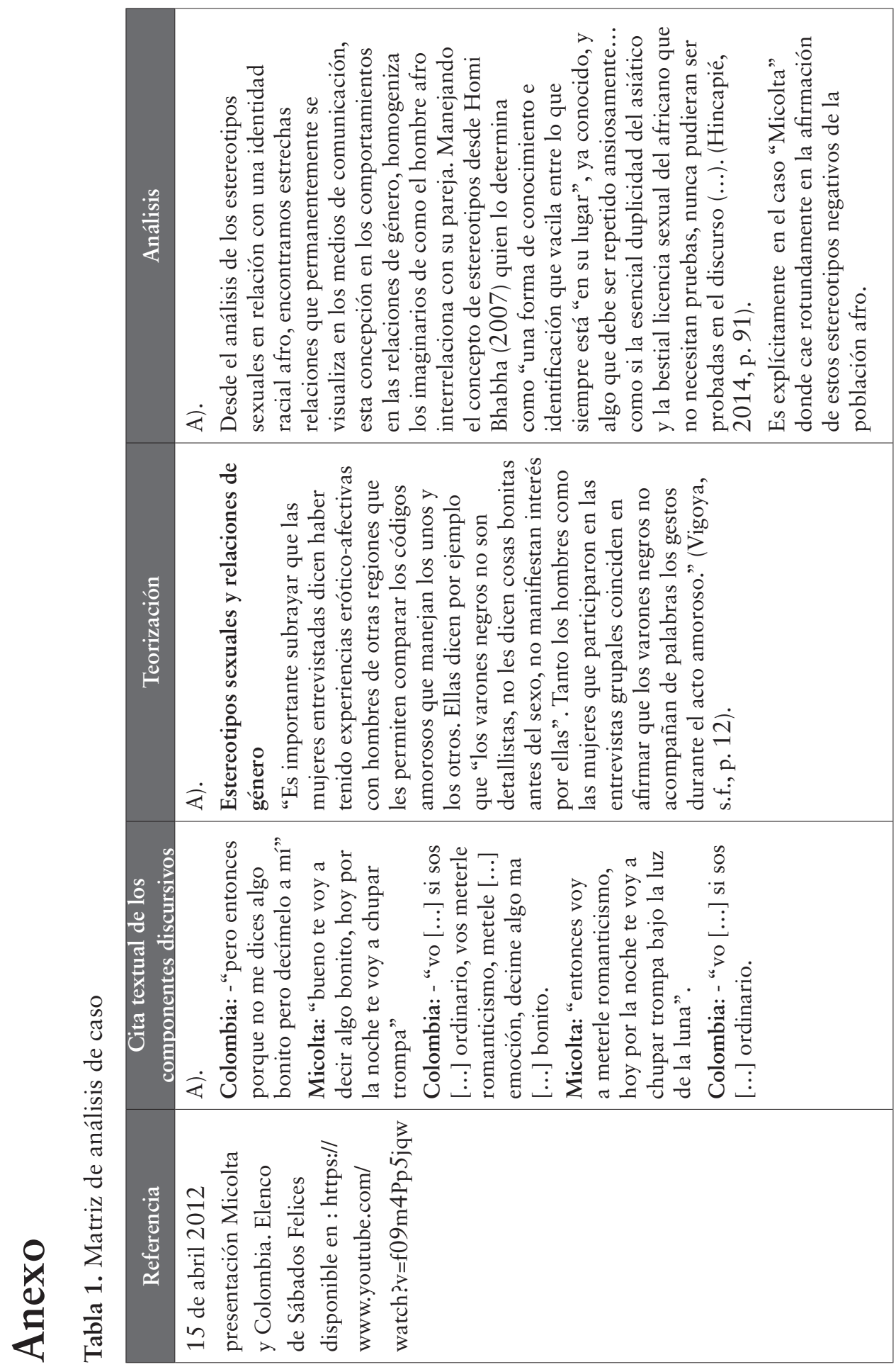


Entre lo individual y lo COlectivo. Cuestiones Afrocolombianas

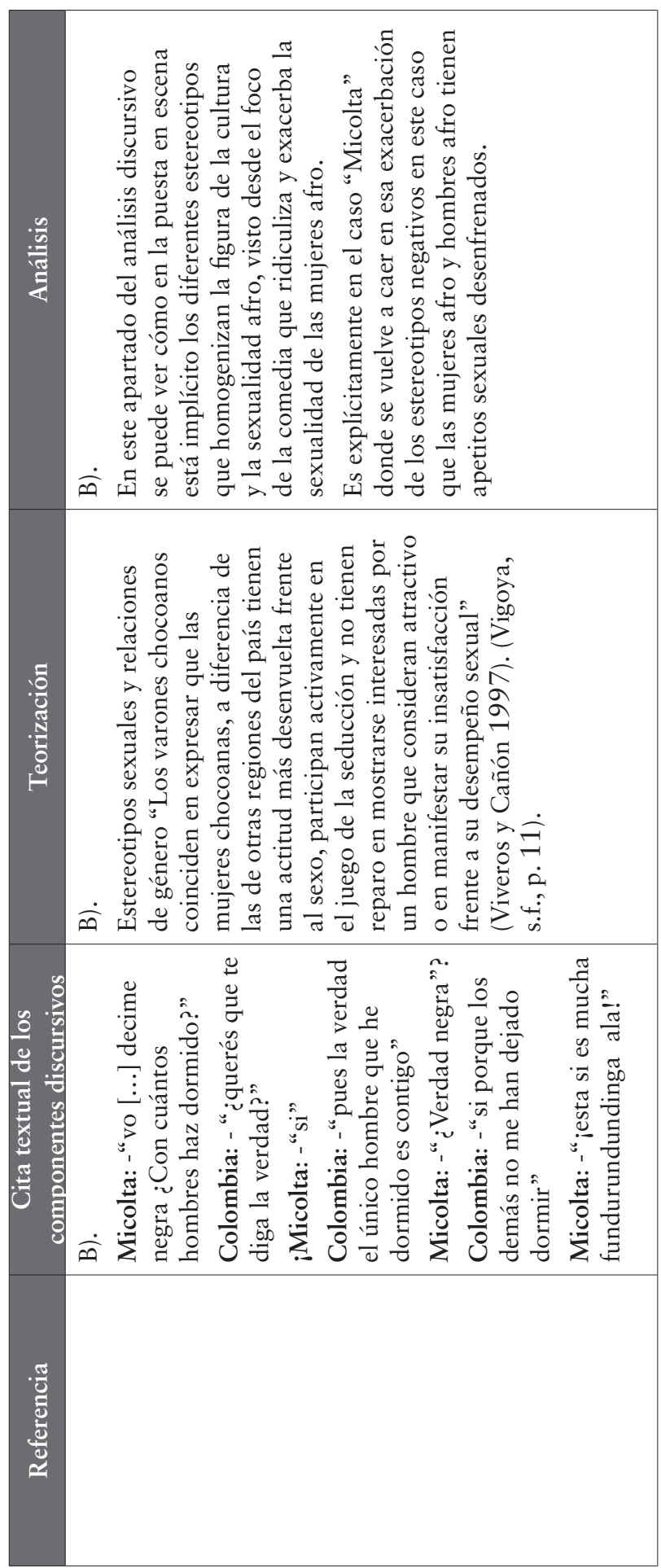




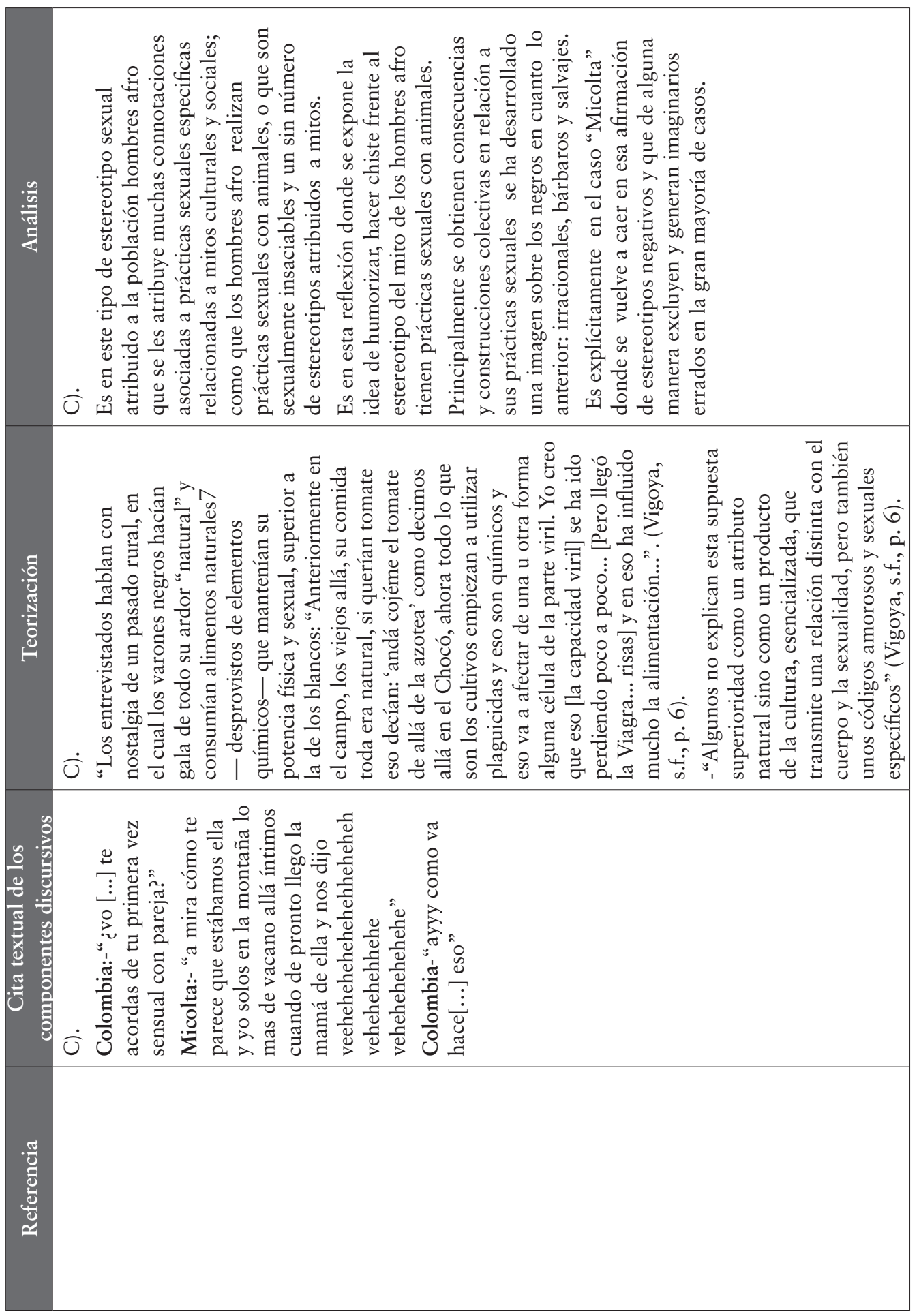




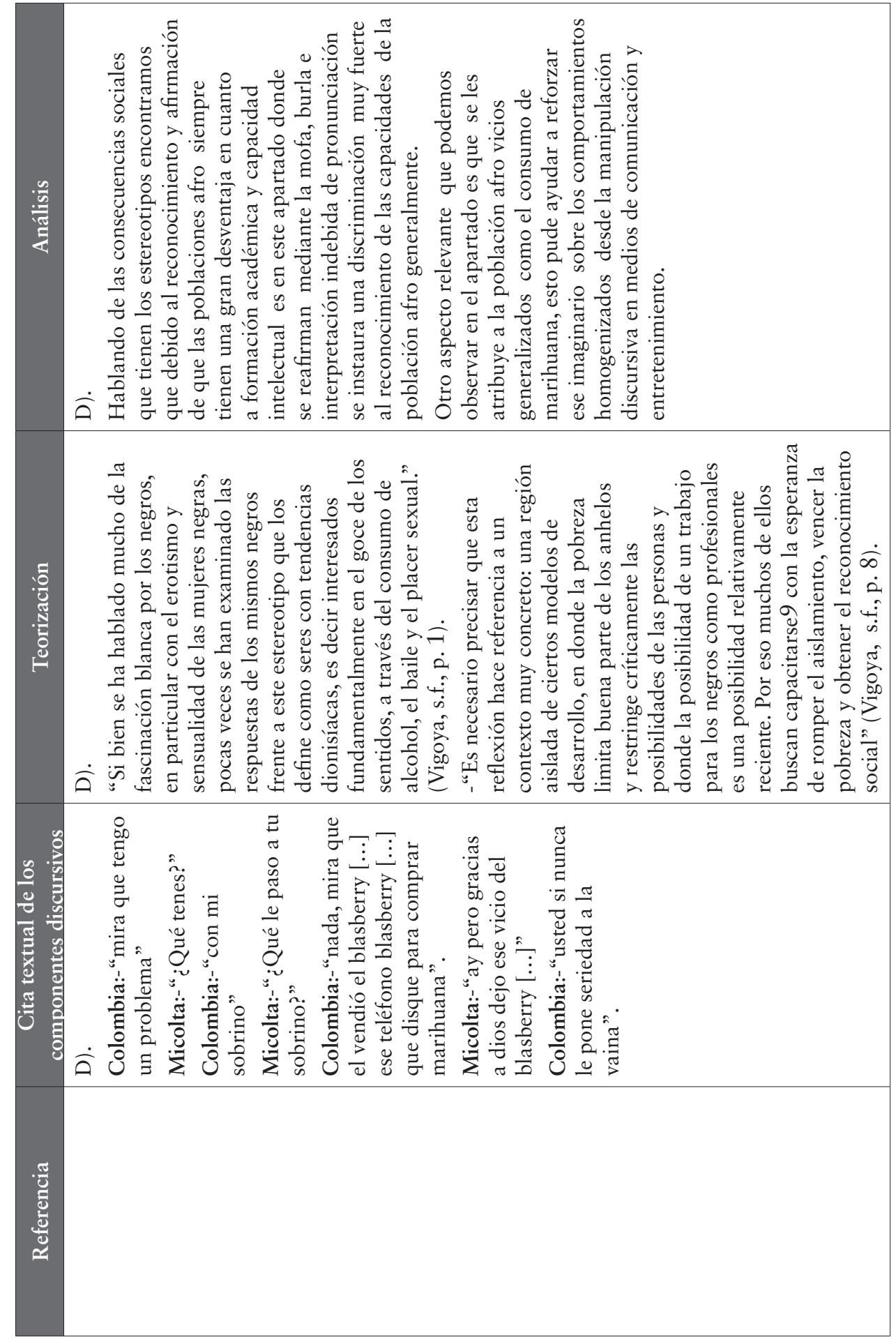

